\title{
Premature mortality: Europe's persisting Iron Curtain?
}

\author{
Mateusz Zatoński ${ }^{1,2}$, Witold A. Zatoński ${ }^{1,3}$, Andrzej Wojtyła ${ }^{4}$ \\ ${ }^{1}$ Health Promotion Foundation, Nadarzyn, Poland \\ 2London School of Hygiene and Tropical Medicine, London, UK \\ ${ }^{3}$ Maria Skłodowska-Curie Memorial Cancer Center and Institute of Oncology, Warsaw, Poland \\ ${ }^{4}$ Higher Vocational State School in Kalisz, Poland
}

\begin{abstract}
One of the chief arguments of advocates of European Union (EU) accession in Central and Eastern Europe (CEE) was that EU membership will help CEE states to catch up with the more developed Western European countries. The economic and technological chasm that existed between the two parts of the continent was closely echoed by the enormous gap in premature adult mortality levels. This health gap was present throughout the $20^{\text {th }}$ century. Intensive efforts to control infectious diseases in the Soviet bloc allowed the life expectancy figures of CEE states to almost catch up with the West in the 1960s, but in the subsequent decades the health gap widened again. This was largely due to the man-made disease epidemic that engulfed the CEE region as a result of over-medicalisation of health, persisting low levels of health literacy, and unhealthy lifestyles (high levels of smoking and alcohol consumption, poor diets). The collapse of communist regimes in 1989 and the following years led to another change in health trends in CEE countries. Antiquated models of healthcare were abandoned, market economy helped precipitate positive changes in diet, a reduction in smoking and alcohol consumption were observed in many countries. However, even after 25 years of improvement, health in CEE countries remains significantly behind Western Europe, and while huge advances have been made in some areas in many countries (e.g. tobacco control), there is still much to be done in others (e.g. limiting alcohol consumption). Currently, three distinct health zones can be identified in Europe. The first is Western Europe, where mortality before 65 in many countries is in single-digit figures. The second are the CEE countries, where one if three men die before the age of 65 . The third is Russia and the former Soviet states, where over half of all men do not life to the age of 65 .
\end{abstract}

KEY WORDS: health inequalities, health gap, Eastern Europe, premature mortality, chronic diseases.

ADDRESS FOR CORRESPONDENCE: Mateusz Zatoński, London School of Hygiene and Tropical Medicine, Keppel Street, London WC1E 7HT, UK, phone: +44 7415240 171, e-mail: mateusz.zatonski@lshtm.ac.uk

\section{INTRODUCTION}

At the beginning of the $21^{\text {st }}$ century ten formerly communist Central and East European (CEE) states entered the European Union (EU). The rhetoric of their policymakers justifying the accession centred on the opportunity EU membership would give the new member-states to catch up with the more developed Western European countries. The economic and technological chasm that existed between the two parts of the continent was closely echoed by the enormous gap in prema- ture adult mortality levels. The difference in life expectancy at birth between the existing member states and the accession countries amounted to almost 7 years in men and almost 5 years in women. In one of the most striking examples, on the eve of EU accession, male life expectancy at birth in the Baltic countries was about 12 years shorter than in nearby Sweden [1].

Today, while the political Iron Curtain dividing Europe is long gone, the health divide between the two parts of the continent remains still very much in place. 
A

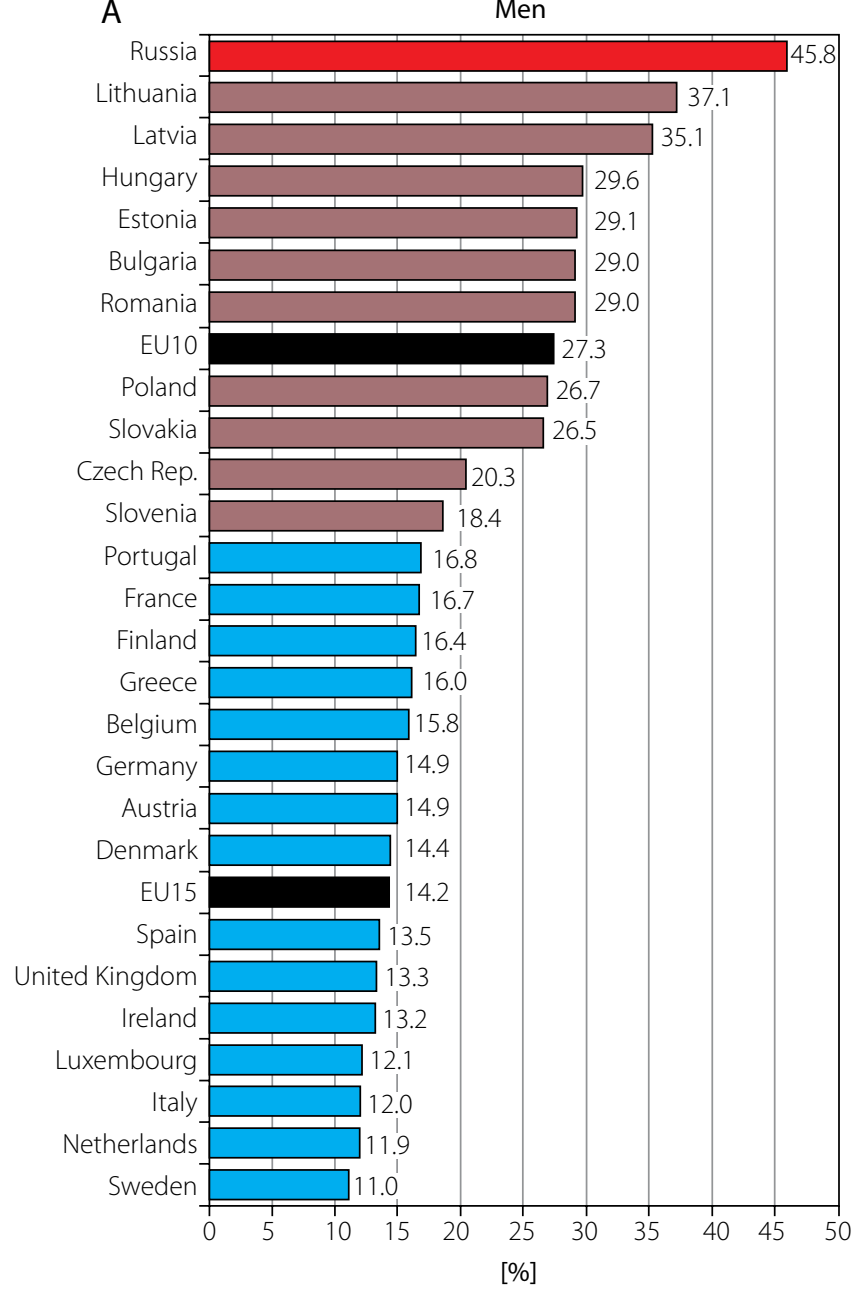

FIG. 1. Probability of dying before age 65, 2012

While Western European countries have seen their death rates before 65 years of age fall to under $10 \%$, in Russia and some countries of the former Soviet Bloc only around 1 in 2 of their male citizens live to this age (Fig. 1) [1].

\section{EUROPE'S HEALTH GAP IN THE $20^{\text {TH }}$ CENTURY}

Over half a century ago things were very different. As the ideologically-driven state socialist health services were set up in the Soviet bloc countries, medical care became available to a wider proportion of society than ever. The improvement of standards of hygiene, compulsory free vaccinations, and the development of sanitary-epidemiological services allowed for a very effective control of infant, child and adolescent mortality, maternal mortality, as well as infectious diseases in general. Life expectancy at birth in Poland, for example, increased by almost 10 years in the 1950s. In Western Germany in the same period it increased by only 2.5 years. By the mid-1960s the average life expectancy figures for Eastern Europe and the more advanced market economy countries of Western Europe were separated by only 1-2 years. The health gap between Eastern and Western Europe was almost closed [1].
B

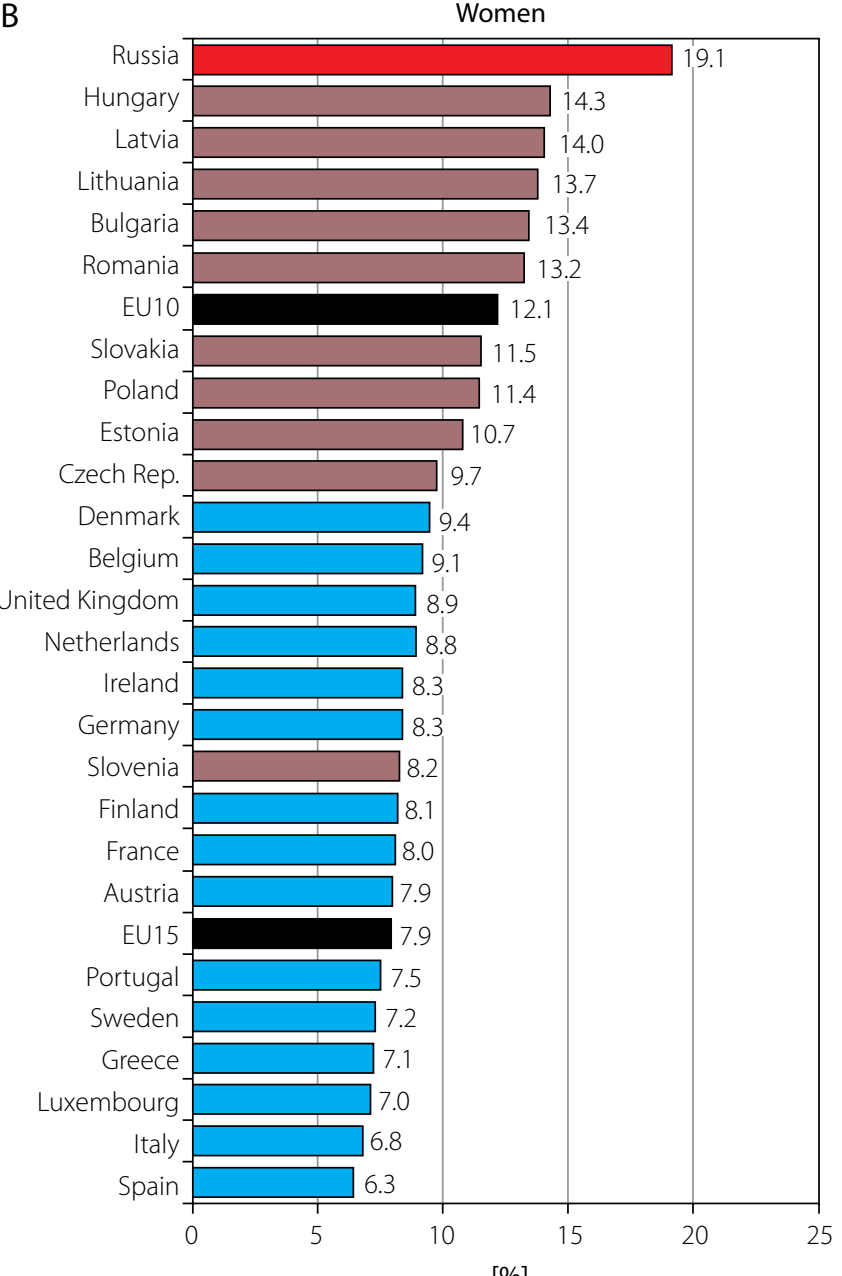

[\%]

However, Eastern Europe was soon to be left behind. Western countries increasingly began to see health not only in terms of hospitals and doctors, but also in the building of health competences of their populations. Public campaigns encouraging healthy diets and physical activity were launched, and governments actively combated vices such as binge drinking and smoking through the imposition of taxes and the rising of minimum prices. Finland serves as a role model for this transformation - from the country with the poorest health in Europe in the 1960s it transformed into one of Europe's health leaders by the end of the century [2].

While populations of Western countries were undergoing the process of building health literacy, in the Soviet sphere public health policy remained frozen. The East European states were focused on building medical infrastructure and training curative medicine personnel. Numbers of physicians and hospital beds in CEE countries were constantly increasing, as was access to new medical procedures and drugs [3]. At the same time consumption of cigarettes and alcohol was growing - both products were ubiquitous and cheap, and there was no effort to increase the public awareness of risks connected 
with them. In fact smoking rates were highest among the wealthiest and best educated segment of society, including medical doctors. In 1990, just before the collapse of the Soviet Union, numbers of doctors per 1,000 inhabitants amounted to 4.7 in Socialist economy countries, and 2.5 just in the established market economy countries [3]. In the same year, Poland became the global leader in smoking prevalence. For a more comprehensive discussion of health development and health policy in Eastern European communist states, see Health in the Polish People's Republic (pp. 7-16).

As communism released Eastern Europe from its grip, things began to change. In the 1990s, after 25 years of health decline, Poland and the other countries of the region, which were to join the European Union in 2004, began to undergo a process of health gain. As the antiquated Soviet model of healthcare was abandoned, modern health policies modelled on the Western experiences were implemented. The results came quickly. Indicators such as cardiovascular mortality, which in the late 1980s were among the worst in the world in CEE countries, began to rapidly improve. The introduction of market economy helped precipitate positive changes in diet, which until the 1990s were impossible due to the limited selection of foodstuffs in the region. For a more detailed discussion of this facet of health change in the region see Unsaturated fat and cardiovascular health in Poland (pp. 63-66).

A reduction in smoking and alcohol consumption also followed. The region entered a phase of health transformation that took place in Western Europe 20 years earlier. For further details on the health improvement that occurred in the 1990s in CEE countries, see Democracy is healthier - health in Poland in the late 1980s and 1990s (pp. 17-24). For a case study of the improvement in tobacco control policy in Poland, see Poland's antitobacco advocacy - a historical outline (pp. 26-31), and The significance and impact of the Polish Anti-tobacco Law (pp. 32-35). See also Trends in smoking among Polish and Norwegian youth 1986-2014 (pp. 44-51).

\section{EUROPE'S HEALTH GAP TODAY}

In 2014 the EU celebrated the tenth anniversary of the first round of accession of CEE states. A decade on, colossal differences in access to health still exist between Eastern and Western Europe, especially in adult mortality. While huge strides have been made towards closing the economic gap, narrowing of the health gap has been more challenging and taken a much slower course. Advances in health policy within CEE countries have also been patchy with success stories such as declining smoking prevalence across the region standing in stark contrast with the decision of some governments to slash the prices of spirits (for example Poland in 2002) [4]. States such as Poland or Russia still have not found effective responses to the problem of alcohol. For a sys- tematic review of attempts to use mass media campaigns in reducing drinking and driving see Are mass media campaigns effective in reducing drinking and driving? (pp. 52-60).

Health inequalities within CEE countries between different educational and income groups, marginal two decades ago, have seen a steep growth. While in absolute terms the health situation in the new EU member states is improving, the gap dividing them from Western Europe has not diminished, since the latter has not stood still either. The mortality decline in Poland in the last two decades has been accompanied by a similar fall in the UK. The persisting health gap within the EU is an important factor destroying human capital and compromising Eastern Europe's chance for future sustainable economic progress [5]. For a case study of decision-making on a critical EU health policy issue, the Tobacco Products Directive, see Evidence-based policy making? The case of Polish opposition to the EU Tobacco Products Directive (p. 36-39).

The Closing the health gap in European Union report [1], published in 2008, was the first comprehensive attempt to document these differences - see http://www.hem.waw. $\mathrm{pl}$. It found that the biggest contributors to the health gap were cardiovascular diseases (contributing to more than half of the gap in men and almost $80 \%$ in women) and injuries (17\% in men and 6\% in women). The higher volume and more irregular pattern of alcohol consumption in the east, combined with the delayed onset of the tobacco smoking epidemic, were found to be the principal lifestyle factors underpinning the health gap.

Nonetheless, CEE states have at least managed to turn away from the course taking them towards a health catastrophe - the same cannot be said about Russia. Russia's health decline began in the 1960s, and not, as is often said, after the collapse of the Soviet Union. Its causes should be sought in underlying systemic reasons, and not just in the economic, social and political earthquake of the 1990s, which simply served to deepen the existing health problems. Today, the health parameters of adults in Russia remain frozen at the same levels they were fifty years ago, despite major fluctuations in life expectancy observed throughout this period. In the early 1960s life expectancy amounted to 69 years, and at the end of the first decade of the $21^{\text {st }}$ century it stood at 67 years. Alcohol is the leading cause of premature mortality among young men in Russia [6]. Smoking remains another major obstacle to building a healthier Russian population - for an action plan on tackling this problem see Policy recommendation to members of the Russian Federal Government: Strong tobacco control measures as a key to reducing mortality (pp. 40-43).

\section{EUROPE'S PERSISTING IRON CURTAIN?}

Two overarching patterns emerge from the current premature mortality figures for Europe. First of all, there is the persisting major difference between the sexes across 


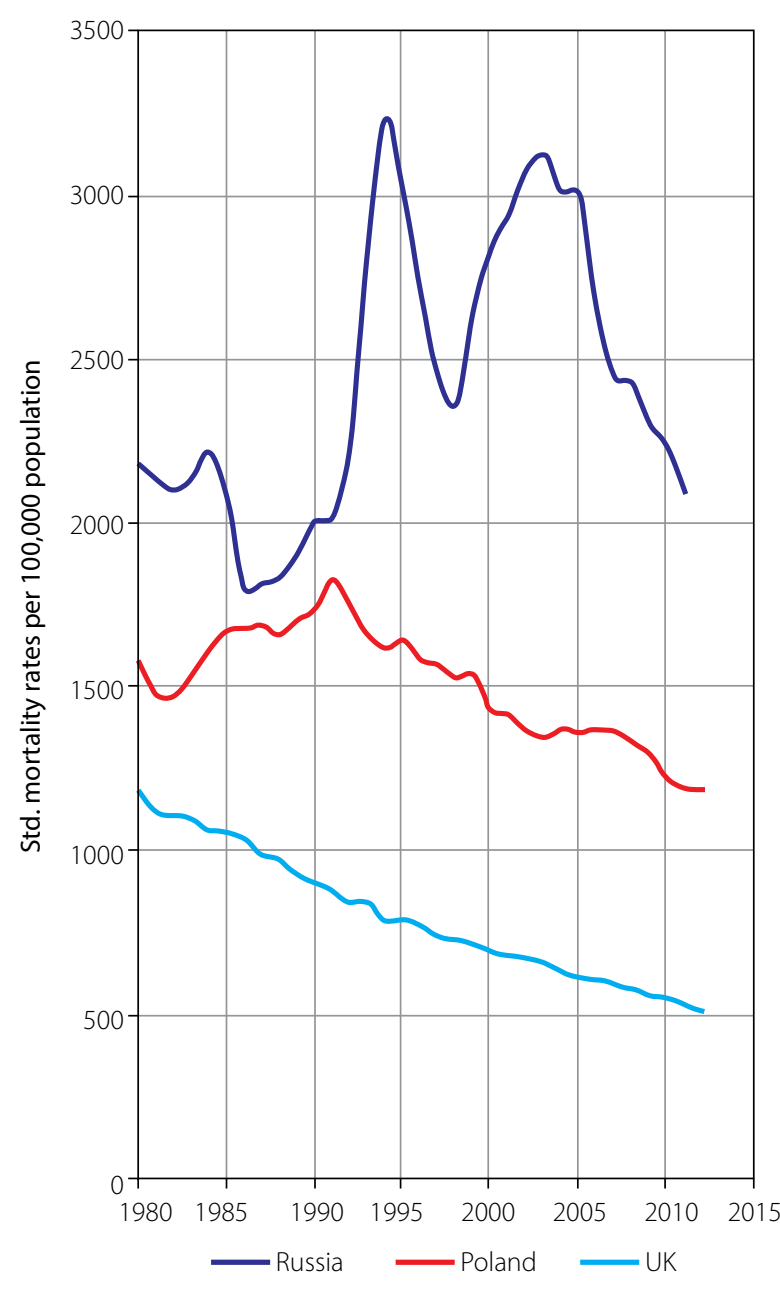

FIG. 2. All-cause mortality, 45-64, in Russia, UK, and Poland per 100,000 inhabitants, 1980-2008

Europe. On average, women are twice more likely to live to 65 than men. This is the result of an incredible decline in female mortality that has been taking place over the last 50 years. In some European countries, such as Spain, Italy, or Sweden, around 5\% of women die before 65 years of age. This stands in stark contrast with males in Russia and other former Soviet Union countries, almost half of whom die before 65 years of age (see Fig. 1).

Second, rather than an Iron Curtain splitting Europe in half, it can be argued that the continent is currently divided into three "health zones" in its health development. The top performers of this "three-speed Europe" are the Western European countries, which have experienced a systematic health gain since the mid- $20^{\text {th }}$ century, and where mortality before 65 is in single-digit figures. Next come the CEE countries, where health gain has been progressing in the last 20 years, and has been preceded by a long period of health stagnation. The rapid economic progress in this region has still not helped to close the health gap with Western Europe, and some differences are widening. In this region, one in three men do not live to the age of 65 . Finally, poorest performers of the "three-speed Europe" are Russia and most former Soviet states. With little or no health gain since the mid$20^{\text {th }}$ century, and over half of all men dying before age 65 , this is one of the only regions in the world, where life expectancy has not increased in the last half century (see Fig. 2). This state of "perpetual health catastrophe", in which the country has been frozen, extols an enormous price in the lives of millions of its citizens.

In the case of the CEE countries and Russia rapid action targeted against preventable diseases and their causes is required if the European public health community is serious about closing the health gaps still existing within the continent.

\section{DISCLOSURE}

Authors report no conflict of interest.

\section{References}

1. Zatoński W and the HEM Project team. Closing the health gap in European Union. Cancer Center and Institute, Warsaw 2008.

2. Stahl T, Wismar M, Ollila E, et al. (ed.). Health in All Policies. Prospects and potentials. Ministry of Social Affairs and Health, Helsinki 2006.

3. Feachem R. Health decline in eastern Europe. Nature 1994; 367: 313-314.

4. Zatoński W, Sulkowska U, Zatoński M, et al. Alcohol taxation and premature mortality in Europe. Lancet 2015; 385: 1181.

5. Zatoński WA, Bhala N. Changing trends of diseases in Eastern Europe: closing the gap. Public Health 2012; 126: 248-252.

6. Zaridze D, Lewington S, Boroda A, et al. Alcohol and mortality in Russia: prospective observational study of 151000 adults. Lancet 2014 ; 383: 1465-1473. 